\title{
Hurricanes and child health: lessons from Cuba
}

\section{Deybis Sánchez Miranda, Imti Choonara²}

\begin{abstract}
HURRICANES
A hurricane is a large rotating storm with a central area of very low pressure and strong winds greater than $74 \mathrm{mph}(118 \mathrm{~km} / \mathrm{h}){ }^{1}$ The hurricane is graded $1-5$ in relation to the strength of the winds, which can be greater than $155 \mathrm{mph}(249 \mathrm{~km} / \mathrm{h}$, category 5). ${ }^{2}$ Hurricanes arise from warm, moist air from tropical oceans, and with global warming, hurricanes are occurring more frequently and with greater severity. ${ }^{3}$ Tropical storms originating in the Atlantic Ocean or the Eastern North Pacific Ocean (ie, the Northern hemisphere) are termed hurricanes, whereas those that originate from the Pacific Ocean are known as typhoons and those from the Indian Ocean as cyclones. ${ }^{1}$ Hurricanes are a major problem for countries in the Caribbean and Central and Latin America. The word 'hurricane' is thought to be derived from either the Carib god 'Hurican' or the Mayan god 'Hurakan,' who caused a great storm and flood by blowing his breath across the ocean. ${ }^{4}$
\end{abstract}

\section{HEALTH EFFECTS}

It has been estimated that almost two million people worldwide have died from tropical storms (hurricanes, typhoons and cyclones) in the last two centuries. ${ }^{1}$ In the 20th century alone, there have been 75000 deaths from hurricanes in North America and the Caribbean, including almost 10000 deaths from hurricane Mitch, which affected Central America in 1998. ${ }^{5}$

The impact of hurricanes on health can be divided into immediate and

${ }^{1}$ Children's Hospital, Camagüey, Cuba

${ }^{2}$ Academic Division of Child Health, University of Nottingham, Derbyshire Children's Hospital, Derby, UK

Correspondence to Professor Imti Choonara, Academic Division of Child Health, The Medical School, University of Nottingham, Derbyshire Children's Hospital, Uttoxeter Road, Derby DE22 3DT, UK; imti.choonara@nottingham.ac.uk

\section{(6) UNLOCKED}

This paper is freely available online under the BMJ Journals unlocked scheme, see http:// adc.bmj.com/info/unlocked.dtl during the recovery phase. Drowning during the hurricane used to account for the majority of the deaths. The use of warning systems combined with evacuation has, however, dramatically reduced drowning deaths. ${ }^{1} 3$ During hurricane Katrina, however, two-thirds of the fatalities were thought to be due to the direct physical effects of the flood, and the majority of the deaths were thought to be due to drowning. ${ }^{6}$ The high number of deaths due to drowning following hurricane Katrina was probably associated with the inadequate evacuation and preparation of the population. ${ }^{7}$ Hurricanes also cause death by physical damage to buildings and trees, which may result in direct trauma. The most frequent injuries following hurricanes are cuts, lacerations, puncture wounds and blunt trauma caused by flying glass and other debris. ${ }^{1} 8$

There are significant health effects after the hurricane when there may be a lack of clean water, food and housing as well as access to healthcare. The lack of provision of these essential items undoubtedly contributed to the significant mortality following hurricane Katrina. ${ }^{9} 10$ Infectious diseases may increase dramatically following a tropical storm. This increase in infectious diseases is more likely to occur in low- and lower-middle income countries. Damage to water and sanitation networks, alongside pools of stagnant water following flooding, may result in a significant increase in cases of gastroenteritis and other infectious diseases. Hurricane Mitch resulted in increases in the number of cases of cholera, leptospirosis, dengue and malaria in several of the affected countries. ${ }^{5}$ Shelter for families who have been evacuated or whose homes have been destroyed is critical for survival. Fatalities following the cyclone in Bangladesh in 1991 were significantly higher in areas where shelter was not provided. ${ }^{11}$

There is increasing recognition that following hurricanes and other natural disasters, there may be significant mental health problems. ${ }^{12}$ The most frequent psychological disorder following natural disasters is post-traumatic stress disorder (PTSD). ${ }^{13}$ Children appear to be more prone to PTSD than adults following natural disasters. ${ }^{12}$ The prevalence of PTSD appears to be related to the severity of the natural disaster and the proximity of the child or adolescent to the event. ${ }^{12}$ Studies in children following hurricanes have shown the prevalence rate of PTSD has ranged from $7 \%$ to $90 \%$ in severely affected regions in Nicaragua following hurricane Mitch. ${ }^{14}$ The symptoms of PTSD can be present for a long period after the hurricane; $12 \%$ children had severe symptoms of PTSD 10 months after hurricane Andrew. ${ }^{15}$ It is important therefore to recognise that the health effects of hurricanes can last well beyond the initial period of impact.

\section{CUBA}

In the summer of 2008, over a period of 3 weeks, two category 4 hurricanes (Gustav and Ike) caused over 200 deaths in the Caribbean and the USA. ${ }^{16} 17$ The two hurricanes were at their greatest intensity (category 4) in Cuba and caused widespread destruction to buildings, livestock and crops. Hurricane Ike alone damaged over 300000 homes in Cuba. ${ }^{17}$ Extensive damage to crops has been reported, and the economic cost to Cuba has been estimated as US\$3-4 billion. ${ }^{17}$ The two hurricanes were of far lower intensity (categories 1 and 2) when they passed through Haiti and the USA.

Despite the fact that Cuba experienced the hurricanes at their greatest intensity, there were only seven deaths throughout Cuba. ${ }^{16} 17$ In contrast, there were over 100 deaths in Haiti and over 30 in the USA. ${ }^{16} 17$ Over the last 50 years, Cuba has managed to reduce significantly the number of deaths following hurricanes. ${ }^{18} 19$ Hurricane Flora in 1963 resulted in the deaths of over 1200 people in Cuba. ${ }^{18}$ Since then, Cuba has introduced early warning systems alongside evacuation. Hurricane Ike passed directly through the Province of Camagüey, and the steps taken to protect the health of children and adults are important for other countries.

\section{WARNING AND PREPARATION}

Because hurricanes originate in the middle of oceans, it is several days before the hurricane reaches land, and this allows governments to take action to protect human life. Cuba has an excellent meteorological institute which, in conjunction with US scientists, projects 
the likely paths of hurricanes. The benefits of universal education and eradication of illiteracy are that the population is aware of the risks associated with hurricanes and understands government warnings. The importance of issuing early warnings to the population cannot be overemphasised and has been shown to be effective in reducing deaths for a variety of extreme weather events. ${ }^{3}$ It is important to recognise that Cuba has a population with a very high level of civil participation. The majority of the population are members of different mass organisations, and there is a strong sense of community spirit.

Hurricane awareness is taught in schools, and $72 \mathrm{~h}$ prior to a hurricane, national media issue alerts are given while civil protection committees check evacuation plans and shelters. ${ }^{20}$ Following hurricane Dennis in 2005, which resulted in 17 deaths within Cuba, a greater awareness of the risks associated with hurricanes has been emphasised to the Cuban population. ${ }^{19}$ Forty-eight hours prior to the hurricane, authorities inform highrisk areas and evacuation commences. Prior to hurricane Ike, 2.6 million people ( $23 \%$ of the population of Cuba) were evacuated and housed in shelters. ${ }^{17}$

\section{PREPARATION IN CAMAGÜEY PROVINCE}

Prior to the hurricane reaching Camagüey province, which has a population of just under 800000 , senior health professionals identified groups that were at the greatest risk. This included approximately 300 children with significant medical problems, 8000 infants and 4000 pregnant women. Children were discharged from the hospital where appropriate, and the emergency departments were prepared for admissions. Paediatric health professionals were allocated to each of the evacuation centres. In the $24 \mathrm{~h}$ following hurricane Ike, there were over 500 emergency cases presenting to the Children's Hospital in Camagüey. Ninety-six of these children required admission, and four required surgery.

\section{RECUPERATION STAGE}

Healthcare following the hurricane is essential. In particular, the importance of hygiene and sanitation was emphasised to minimise the increase in acute gastroenteritis. Following the hurricane, there was a $10 \%$ increase in gastroenteritis. Within a week of the hurricane, all 8000 infants in Camagüey Province were visited in their homes by the family doctor, nurse or other health professional. This was only possible because Cuba has one of the best primary healthcare systems in the world with the highest ratio of doctors per capita worldwide. ${ }^{21} 22$ Each family doctor and nurse is responsible for between 120 and 160 families. Health professionals kept a special lookout for mental health problems in children following the hurricane, as it is recognised that these are significant problems. ${ }^{23}$

\section{CONCLUSIONS}

The economic damage caused by hurricanes Gustav and Ike (two category four hurricanes) to Cuba was substantial. However, by a combination of early warnings and preparation alongside the evacuation of almost a quarter of the population of Cuba, only seven lives were lost (box 1). Both Jamaica and the Dominican Republic have used the mass media in a similar manner to Cuba to try and increase awareness among individuals of the dangers associated with hurricanes and how appropriate preparation can reduce casualties. ${ }^{20}$ Equally important as preparation prior to the hurricane is ensuring the provision of shelter, food and water alongside healthcare after the hurricane for all individuals in affected areas (box 1). This should be provided by the government of the affected country and is easier to provide if there is universal healthcare. As extreme weather events are likely to increase with climate change, it is important that other countries take on board the Cuban experience in order to minimise the loss of human lives.

\section{Box 1 Measures to minimise casualties for hurricanes}

Before the hurricane

- Early warning and preparation of population

- Organised evacuation

- Identification of groups at risk

After the hurricane

- Provision of shelter, food and water

- Provision of healthcare, especially to groups at risk

\section{Competing interests None.}

Provenance and peer review Commissioned; externally peer reviewed.

Accepted 28 July 2010

Published Online First 22 September 2010

Arch Dis Child 2011;96:328-329

doi:10.1136/adc.2009.178145

\section{REFERENCES}

1. Shultz JM, Russell J, Espinel Z. Epidemiology of tropical cyclones: the dynamics of disaster, disease, and development. Epidemiol Rev 2005:27:21-35.

2. National Hurricane Center. http://www.nhc noaa.gov/pdf/NWS-TPC-5.pdf (Accessed 15 December 2009).

3. Ebi KL, Schmier JK. A stitch in time: improving public health early warning systems for extreme weather events. Epidemiol Rev 2005;27:115-21.

4. National Oceanic and Atmospheric Association. Hurricane Research Division http:// www.aoml.noaa.gov/hrd/tcfaq/B4.html (Accessed 27 January 2010).

5. Pan American Health Organization. Impact of hurricane Mitch on Central America. Epidemiol Bull 1998:19:1-13.

6. Jonkman SN, Maaskant B, Boyd E, et al. Loss of life caused by the flooding of New Orleans after Hurricane Katrina: analysis of the relationship between flood characteristics and mortality. Risk Anal 2009;29:676-98.

7. Susman J. A case that's black and white: the price of being poor and African American in New Orleans. J Fam Pract 2005;54:832.

8. Linscott AJ. Natural disasters_a microbe's paradise. Clin Microbiol News/ 2007;29:57-62

9. Ferdinand KC. Public health and Hurricane Katrina: lessons learned and what we can do now. J Natl Med Assoc 2006:98:271-4.

10. Atkins D, Moy EM. Left behind: the legacy of hurricane Katrina. BMJ 2005;331:916-18.

11. Bern C, Sniezek J, Mathbor GM, et al. Risk factors for mortality in the Bangladesh cyclone of 1991 Bull World Health Organ 1993;71:73-8.

12 Sundram S, Karim ME, Ladrido-Ignacio L, et al. Psychosocial responses to disaster: an Asian perspective. Asian J Psychiatr 2008;1:7-14.

13. Norris FH, Friedman MJ, Watson PJ, et al. 60,000 disaster victims speak: Part I. An empirical review of the empirical literature, 1981-2001. Psychiatry 2002;65:207-39.

14. Goenjian AK, Molina L, Steinberg AM, et al. Posttraumatic stress and depressive reactions among Nicaraguan adolescents after hurricane Mitch. Am J Psychiatry 2001:158:788-94.

15. La Greca A, Silverman WK, Vernberg EM, et al. Symptoms of posttraumatic stress in children after hurricane Andrew: a prospective study. $J$ Consult Clin Psychol 1996;64:712-23.

16. National Hurricane Center. http://www. nhc.noaa.gov/pdf/TCR-AL072008 Gustav.pdf (Accessed 14 December 2009).

17. National Hurricane Center. http://www.nhc. noaa.gov/pdf/TCR-AL092008 Ike.pdf (Accessed 14 December 2009).

18. Mesa G. The Cuban health sector and disaster mitigation. MEDICC Review 2008;10:5-8.

19. Reed G. You can't stop the rain: José Betancourt, MD. MEDICC Review 2008;10:14-16.

20. International Federation of Red Cross and Red Crescent Societies. World Disasters Report 2005. Chapter Two: Run, Tell Your Neighbour! Hurricane Warning in the Caribbean. http://www. ifrc.org/publicat/wdr2005/chapter2.asp (Accessed 11 February 2010)

21. Rodriguez FV, Lopez NB, Choonara I. Child health in Cuba. Arch Dis Child 2008:93:991-3.

22. Lopez NB, Choonara I. Can we reduce the number of low-birth-weight babies? The Cuban experience. Neonatology 2009; 95:193-7.

23. Osofsky HJ, Osofsky JD, Kronenberg M, et al. Posttraumatic stress symptoms in children after Hurricane Katrina: predicting the need for mental health services. Am J Orthopsychiatry 2009;79:212-20. 